\title{
Impacts of shifting to healthier food consumption patterns on environmental sustainability in MENA countries
}

\author{
Rachel Bahn ${ }^{1} \cdot$ Sibelle EL Labban ${ }^{1} \cdot$ Nahla Hwalla $^{1}$
}

Received: 19 December 2017 / Accepted: 26 June 2018/Published online: 14 July 2018

(C) The Author(s) 2018

\begin{abstract}
Middle East and North Africa (MENA) countries face considerable challenges in achieving the sustainable development goals (SDGs). Reducing the escalating diet-related non-communicable diseases (NCDs), combatting food insecurity, and preserving environmental resources are major issues and these countries are struggling to address. The adoption of sustainable and healthy diets is proposed as a measure that would deliver both environmental and health benefits to these countries. Whether shifting to a recommended healthier food consumption pattern affects the environmental sustainability of the region needs to be investigated. This study assesses the environmental footprints - total and blue water, energy use, and greenhouse gas emissions (GHGE) — of four food groups (red meat, vegetables/beans, nuts/seeds, and fruits), shown to be associated with the burden of NCDs. Footprints of current and nutritionally recommended consumption levels were calculated, and the net savings or expenditure for each food group was aggregated across adult populations in each of 17 MENA countries. Results showed that reduced red-meat consumption would generate savings in all four footprints, while higher vegetables/beans, nuts/seeds, and fruits' consumption would yield net expenditure in those footprints. The findings demonstrate the beneficial environmental effects of reducing consumption of red meat, and the tradeoffs that would result from a simultaneous increase in consumption of vegetables/beans, across MENA countries. Further analysis is needed to elucidate the environmental footprints of other recommended changes in food consumption habits that would clarify further potential tradeoffs associated with recommended shifts in the consumption of other protective and harmful foods in the MENA region.
\end{abstract}

Keywords Food consumption · Sustainable diets - Environmental footprints · Middle East and North Africa

\section{Introduction}

The Middle East and North Africa (MENA) region is facing a constellation of challenges that include persistent food and nutrition insecurity, an unprecedented escalation in diet-related non-communicable diseases (NCDs), and

Handled by David J. Abson, LeuphanaUniversitat Luneburg, Germany.

Electronic supplementary material The online version of this article (https://doi.org/10.1007/s11625-018-0600-3) contains supplementary material, which is available to authorized users.

Nahla Hwalla

nahla@aub.edu.lb

1 Faculty of Agricultural and Food Sciences, American University of Beirut, PO Box 11-0236, Riad El Solh, 11072020 Beirut, Lebanon depleted environmental resources, thereby negatively impacting both the health and the environment of their populations. High consumption of harmful foods and low consumption of protective foods have been shown to be associated with higher mortality from chronic diseases ailing the region (Afshin et al. 2015). Adoption of healthy and sustainable diets has been proposed as one of the measures to improve nutritional and environmental outcomes simultaneously (UNDP 2016a).

\section{Food consumption patterns and associated health outcomes in MENA}

Current food consumption patterns in the MENA region have been reported to contribute to multiple forms of dietrelated NCDs. MENA countries have experienced a nutrition transition, characterized by a shift away from traditional, seasonal, and more diverse diets rich in whole 
grains, fruits, and vegetables; towards a Westernized diet rich in refined cereals, animal proteins, fats, and sugars (Johnston et al. 2014). These shifts in food consumption habits have been associated with high prevalence of overweight and obesity and diet-related NCDs (such as diabetes, cardiovascular disease, and cancers) (Popkin 2000; Sibai et al. 2010), whereby an estimated $65 \%$ of adults in MENA countries are overweight and obese, approaching the highest rates worldwide (WHO 2011), while 9\% of children under five are overweight (https://public.tableau. com/profile/unicefdata\#!/vizhome/JointMalnutritionEstima tes2016Edition/UNICEF). In addition, four MENA countries-Kuwait, Qatar, Saudi Arabia, and United Arab Emirates-were ranked in the top twenty for highest obesity worldwide in 2014 (NCD Risk Factor Collaboration 2016); three of these countries (Saudi Arabia, Kuwait, and Qatar) were also among the top 10 in diabetes prevalence worldwide in 2013, and are expected to remain so in 2035 (International Diabetes Federation 2013). Moreover, mortality from cardiovascular diseases in MENA has been estimated to triple from 1990 to 2020 (Yusuf et al. 2001). In addition, the prevalence of hypertension among adults in MENA countries has been reported to range between $19.3 \%$ (in Iraq) and $42.1 \%$ (in Bahrain), while that of metabolic syndrome is between $17.4 \%$ (in Algeria) and 39.6\% (in the United Arab Emirates) (Fahed et al. 2012).

Evidence shows that unhealthy food consumption patterns in the region have significantly contributed to the above-mentioned diet-related NCDs, burdened healthcare systems, and reduced quality of life for millions. In fact, high consumption of processed meat, red meat, transfatty acids, sugar-sweetened beverages, and sodium, labeled harmful, and low consumption of fruits, vegetables and beans, nuts and seeds, whole grains, and seafood omega-3 fatty acids, labeled protective, have been associated with higher mortality from diabetes and cardiovascular diseases across all MENA countries (Afshin et al. 2015). MENA countries have demonstrated insufficient per-capita consumption of the protective foods, well below nutritionally recommended levels, and higher than recommended percapita consumption of harmful foods (Afshin et al. 2015).

\section{Environmental sustainability of food consumption patterns in MENA}

Available evidence suggests that current food production and consumption patterns in MENA countries are also imposing significant environmental costs, and may not be environmentally sustainable. Agriculture consumes nearly $85 \%$ of all water withdrawals in MENA countries (Sadik 2014), a rate exceeding the global average of approximately 69\% (FAO 2016c). Agriculture occupies a third of all land area in the MENA region, roughly on par with the global figure of approximately 38\% (World Bank 2016). Agriculture and land use account for approximately $10 \%$ of total greenhouse gas emissions (GHGE) in the MENA region (FAO 2016a, b; World Resources Institute 2015). GHGE from the agricultural sector increased by approximately $8 \%$ in the MENA region over the period 2000-2012, a rate higher than the global average of less than $2 \%$ over the same period (FAO 2016b). Though the MENA region produces less than 3\% of all global GHGE from its combined agriculture and land use activities (FAO 2016b), this figure accounts only for agricultural production occurring within those countries and excludes the emissions associated with agricultural and food products imported to the MENA region. In fact, given that the MENA region imports large amounts of food to satisfy demand, and is notably the world's largest net importer of cereals (World Bank et al. 2009), sugar, and poultry (Woertz and Keulertz 2015), the footprint associated with food imports to the region (the virtual water, GHGE, and energy footprints, to borrow the terminology of Allan (2000)) is expected to be significant. Moreover, the burden on limited and declining environmental resources is expected to increase as food production expands to feed a rising population in MENA, which will grow to approximately 604 million people by 2050 (UN 2013). Moreover, as demand rises, food imports are expected to increase, and therefore, the ecological footprint associated with MENA's food consumption is likely to increasingly fall outside its geographic borders (Woertz and Keulertz 2015), thereby raising its virtual water, GHGE, and energy footprints.

Consumption and demand of food constitute drivers of production which, in turn, exerts its influence on environmental footprints. According to the Barilla Center for Food and Nutrition (2010), plant-based foods such as grains, fruits, vegetables, and legumes are considered both healthy and of low environmental impact, contributing more to sustainability. Conversely, animal-based foods such as animal fats and beef are associated with poor health outcomes if consumed in large amounts and require significantly more water and energy resources to produce than plant-based foods; and hence are considered less healthy and less sustainable. Thus, MENA countries are not consuming enough of the healthy and more sustainable foods, while they are over-consuming harmful and less sustainable foods, making food consumption patterns in the region both unhealthy and unsustainable. Moreover, high levels of food loss and waste totaling one-third of global food production exacerbate the negative impact on the environment, occupying land resources in the form of landfills, contributing to water pollution, and consuming natural resources that are no longer available for production (Moomaw et al. 2012). The countries of North Africa, West, and Central Asia were responsible for $7 \%$ of global 
food losses and waste in 2009. Moreover, a total of $19 \%$ of all food available in the region was lost or wasted, primarily at the consumption stage, equivalent to approximately 594 kilocalories lost or wasted per person per day (Lipinski et al. 2013).

\section{Sustainable diets advance the Sustainable Development Goals}

So far, efforts to improve food security in many MENA countries have focused primarily on increasing agricultural production with less attention to the quality and sustainability of the food supply, or to the distribution, allocation, and diversity of food consumed by the population (Meerman et al. 2013). Issues of environmental, health-related, social, and economic sustainability have been largely overlooked. Intensive and efficient production technology, processing, and transportation have helped to make food more available, affordable, and convenient; but negatively impacted diets by making food less diverse and less healthy, and contributed to adverse outcomes for human health and the natural environment (Lang and Barling 2012). These outcomes highlight the need for action that targets sustainability, as well as the health of populations.

Addressing the aforementioned challenges in the MENA region may benefit from changes towards healthy and sustainable food consumption patterns that are both protective of the health of populations and of environmental resources alike. Indeed, sustainable and healthy diets have been proposed as a mean to address these challenges, thereby providing MENA countries with the opportunity to join the international commitment towards advancing the Sustainable Development Goals (SDGs) (FAO 2012; HLPE 2017).

The set of 17 SDGs adopted by the UN General Assembly in 2015 aims to address, among others, the root causes of hunger, food insecurity, and NCDs. In doing so, the SDGs have elevated "sustainable diets" to the forefront of the sustainability agenda (UNDP 2016a). For example, SDG 12 calls for sustainable consumption and production patterns for all products including food, with sustainability integrating both health and environmental implications of the food to be consumed. SDG 12 is directly linked to developing sustainable diets that will ensure healthy individuals and protect the environment; its targets include achievement of sustainable management and efficient use of natural resources, though not specifically those linked to food consumption. Sustainable diets are also linked to other SDGs, notably SDG 2, which seeks to end hunger, achieve food security, improve nutrition, and promote sustainable agriculture, and SDG 3, which seeks to ensure healthy lives and promote well-being for all at all ages and specifically to reduce premature death from NCDs (UNDP 2016b).
However, neither SDG 2 nor SDG 3 includes targets concerning the environmental impact of food consumption.

The Food and Agriculture Organization of the United Nations (FAO) (2012) has defined sustainable diets as those diets with low environmental impacts which contribute to food and nutrition security and to healthy life for present and future generations. Sustainable diets are protective and respectful of biodiversity and ecosystems, culturally acceptable, accessible, economically fair, and affordable; nutritionally adequate, safe, and healthy while optimizing natural and human resources. This definition makes sustainable diets an important tool and a promising approach towards achieving the SDGs highlighted above through aiming at sustainable consumption and production patterns, food security and improved nutrition, as well as health and well-being for all populations. Sustainable diets promise important benefits for both public health and the environment. Promoting sustainable diets that take into account agricultural systems, environmental systems, food processing and safety, economic development, and nutrition is essential to move forward in promoting sustainable food consumption and production as well as health and well-being, and so help meet the SDGs.

A growing body of academic literature has explored the intersection of diet and sustainability, seeking to understand the environmental implications of nutritionally sound consumption patterns beyond a single food item; across a range of environmental impacts; and in different geographies (Capone et al. 2013; Germani et al. 2014; Green et al. 2015; Heller and Keoleian 2015; Hendrie et al. 2014; Meier and Christen 2013; Tukker et al. 2011; Vanham 2013; Vanham et al. 2013, 2016; Westhoek et al. 2014). The environmental impact of foods or dietary patterns is most often reported in the form of "footprint" measures specific to an agricultural or food product, derived from a life cycle analysis (LCA). These studies have typically determined that adherence to sustainable dietary guidelines could result in substantial savings of total or blue water, energy, GHGE, and/or land use. The evidence is not universal. A systematic review of more than 60 studies reported that, across 210 scenarios assessing a switch to alternative, healthier dietary patterns, 11 scenarios resulted in an increased environmental impact (Aleksandrowicz et al. 2016). For example, Tom et al. (2016) found that adherence to both food mix and caloric intake guidelines would result in increased blue water and energy use and GHGE in the United States, indicating that dietary recommendations may in some cases encompass tensions between nutritional and environmental sustainability. However, evidence generally supports a positive correlation between healthier dietary patterns and environmental sustainability: Aleksandrowicz et al. (2016) also concluded that shifting towards sustainable diets may reduce 
environmental impacts, lowering GHGE and land use by as much as $70-80 \%$ and water use by up to $50 \%$ (median reductions of $20-30 \%$ for all indicators). Similarly, a systematic review conducted by Nelson et al. (2016) of population-level dietary patterns and food sustainability in 10 countries found that adherence to selected dietary patterns including vegetarian and Mediterranean-style diets could promote better health while imposing a less negative environmental impact, as compared to current dietary intakes. However, research in this area specific to the MENA region-indeed, to the developing world-appears to be scarce (Jones et al. 2016).

The purpose of this research is to assess the impact of shifting current food consumption patterns to a recommended one on environmental sustainability across MENA countries. It also highlights tradeoffs needed to secure the health of populations and preserve the environment in MENA. By identifying concrete outcomes that could be achieved through the adoption of nutritionally improved diets, this research seeks to help improve the localization process of the SDGs (specifically SDGs 2, 3, and 12) within the region.

\section{Materials and methods}

Changes in the environmental footprint associated with shifting food consumption to a healthier pattern across countries in the MENA region were calculated. Consumption of four food groups - red meat, vegetables/beans, nuts/seeds, and fruits - was the subject of this study. These groups were selected based on the availability of their consumption data for MENA countries, which forms the basis of the analysis; and their association with mortality from diet-related NCDs. Food groups for which consumption data were not available, or for which a clear association with mortality from diet-related NCDs has not been established within the literature, have been excluded. Current and recommended food intake figures for these food groups were derived from Afshin et al. (2015), who reported consumption figures across most MENA countries, at the national level. Recommended intake figures were constant across countries, in line with general nutrition guidelines for adults. The amount of additional food to be consumed or excess food to be reduced from consumption was calculated in grams per person per day to achieve recommended intake levels ( $\mathrm{S} 1$ ), across each of the four food groups.

This analysis encompasses four distinct environmental footprints: total (blue, green, and grey) water, blue water, energy use, and GHGE. Environmental footprint calculations were based on peer-reviewed, published data, where total and blue water footprint data (liters per kilogram of food) were taken from Mekonnen and Hoekstra (2011); country-level footprint data were used to calculate a simple average that could be applied across the MENA region, rather than a global average (S2). Energy use figures (MJ per kilogram) were taken from Tom et al. (2016) based on aggregation of multiple underlying studies (S3). GHGE figures (kilogram $\mathrm{CO}_{2}$ equivalent per kilogram) were taken from Heller and Keoleian (2015) (S4). In the case of energy use and GHGE figures, global estimates were applied, because region-specific figures were not available. Per-unit footprint data were retrieved for component foods comprising each of the four major food groups indicated above.

Food group footprints were calculated as the simple average of footprints of component foods. Footprints for the red-meat food group were calculated to exclude pork products, given its limited consumption in the MENA countries due to cultural considerations. A list of food components included in each food group and their corresponding average footprints is available as S5.

The net change in environmental footprint across all metrics (total water, blue water, energy use, and GHGE) associated with shifts from current to recommended food consumption patterns was calculated. Calculations were made for an average adult, per country; multiplied by the total adult population (aged 15+) of the country (2015 figures) (United Nations 2013), and summed to reach a regional estimate. This study covers most MENA countries and approximately $87 \%$ of the region's adult population as of 2015. Comoros, Djibouti, Mauritania, Somalia, and Sudan were excluded due to the lack of data availability on current food consumption in those countries. Two conflictaffected countries, Syria and Yemen, are included for the sake of completeness, though available consumption data would reflect pre-conflict rather than current patterns. ${ }^{1}$ The potential, aggregate impact of large-scale dietary changes was thus determined.

Figures of net change in consumption have been adjusted to account for food losses and waste incurred including at the retail and consumer levels, to improve the accuracy of estimated environmental impact. A standard adjustment of $19 \%$ was applied to both current and recommended consumption levels, to account for the additional food to be produced or to be saved. This adjustment was applied uniformly across all MENA countries, reflecting available evidence on food losses and waste within the region (Lipinski et al. 2013).

Sensitivity analysis has been conducted to assess the implications of possible inaccuracies in the point estimates of per-food environmental footprints or the prevalence of

\footnotetext{
${ }^{1}$ Conflict may alter consumption patterns, for example by reducing physical and economic access to food (FAO 2017) and dietary diversity (Dabalen and Paul 2014).
} 
food loss and waste. First, assessment of the sensitivity of results to variation in the per-unit environmental footprint figures was determined. For total and blue water footprints, the analysis builds on MENA-specific per-unit environmental footprints. As data were not available for every country considered in this analysis, a simple cross-country average was used to obtain point estimates. To test the robustness of these point estimates, the minimum and maximum values for the total and blue water footprints perfood group within the MENA region, as well as the global average footprint (Mekonnen and Hoekstra 2011) were applied; and the environmental impact of recommended dietary changes across the region was re-calculated. Next, the robustness of point estimates for energy use and GHGE footprints was tested. The analysis has built upon global per-unit footprint figures as MENA-specific estimates were unavailable. These point estimates were roughly adjusted by the ratio of MENA-to-global footprints across the available water footprints (mean, maximum, and minimum ratios for each of the four food groups in question), and the environmental impact of recommended dietary changes across the region was re-calculated.

Sensitivity analysis has also been conducted with regard to the rate of food loss and waste in MENA countries, to allow for the possibility that rates of loss and waste may differ across food groups. Two-way analyses were performed to assess the impact of plausible variation in food loss and waste rates (ranging from 0 to $40 \%$ ) across pairs of food groups, for each of the four environmental footprints. Pairwise combinations considered red meat and vegetables/ beans, red meat and nuts/seeds, and red meat and fruits.

\section{Results}

Table 1 displays the total net changes in total water footprint, blue water footprint, energy use, and GHGE as a result of the recommended dietary changes, by food group (red meat, vegetables/beans, nuts/seeds, and fruits) across all MENA countries. Reducing consumption of red meat resulted in savings over baseline in terms of total water, blue water, energy use, and GHGE by approximately $78 \%$. Increasing consumption of vegetables/beans, nuts/seeds, or fruits resulted in net expenditure for each of these environmental footprints. For vegetables/beans, the increased consumption would result in expenditures over baseline of total water, blue water, energy use, and GHGE of approximately $64 \%$. For nuts/seeds, the increased consumption would result in expenditures over baseline of total water, blue water, energy use, and GHGE of approximately $79 \%$. For fruits, the increased consumption would result in expenditures over baseline of total water, blue water, energy use, and GHGE of approximately $160 \%$.
Analyzing the data for paired comparisons at the regional level, reduced red-meat consumption paired with increased vegetable/beans consumption (only) would generate net savings in total water, blue water, and GHGE, but net expenditure in energy use. The red-meat-vegetables/ beans paired changes in consumption would result in savings over baseline (the combined sum of baseline for red meat and vegetables/beans) for total water of approximately $38 \%$, for blue water of approximately $16 \%$, and for GHGE of approximately $56 \%$; however, the paired changes would result in expenditure over baseline for energy use of approximately $17 \%$. Reduced red-meat consumption paired with recommended intake of nuts/seeds (only) would generate significant net savings in all four environmental footprints. The red-meat-nuts/seeds paired changes in consumption would result in savings over baseline (the combined sum of baseline for red meat and nuts/seeds) for total water of approximately $71 \%$, for blue water of approximately $71 \%$, for energy use of approximately $76 \%$, and for GHGE of approximately 76\%. Reduced red-meat consumption paired with increased fruit consumption (only) would generate net savings in total water and GHGE, but net expenditure in blue water and energy use. The red-meat-fruits paired changes in consumption would result in savings over baseline (the combined sum of baseline for red meat and fruits) for total water of approximately $54 \%$ and for GHGE of approximately $65 \%$; however, the paired changes would result in expenditure over baseline for blue water of approximately $18 \%$ and for energy use of approximately $52 \%$.

The net changes in total water and blue water, energy use, and GHGE footprints resulting from shifting to recommended dietary patterns in each of the MENA countries are shown in Table 2. Reduced red-meat consumption was associated with the largest savings in total water, blue water, energy use, and GHGE footprints, mostly in Algeria, Egypt, Saudi Arabia, Iraq, and Syria. In fact, these five countries would jointly account for more than $65 \%$ of savings attributable to reduced red-meat consumption, across all four environmental footprints. For all MENA countries, increased consumption of vegetables/beans and fruits was associated with the largest expenditures in total water, blue water, energy use, and GHGE footprints. Changes in consumption of nuts/seeds are associated with a relatively lower magnitude of impact on environmental resources.

Looking at each environmental footprint across MENA countries, total water footprint expenditure appears to be highest in Egypt, Algeria, Morocco, and Saudi Arabia for increased vegetable/beans consumption. The largest blue water footprint expenditures were shown in Egypt, Algeria, Morocco, and Iraq for increased fruits consumption and in Algeria for increased vegetables/beans consumption. 
Table 1 Net changes in total water, blue water, energy use, and GHGE as a result of shifting to recommended dietary changes, by food groups, across MENA countries

\begin{tabular}{|c|c|c|c|c|}
\hline \multicolumn{5}{|c|}{ Environmental footprint of recommended dietary changes-regional level ${ }^{\mathrm{a}}$} \\
\hline & Total water $(\mathrm{L})$ & Blue water $(\mathrm{L})$ & Energy use (MJ) & GHGE $\left(\mathrm{kg} \mathrm{CO}_{2} \mathrm{eq}\right)$ \\
\hline \multicolumn{5}{|l|}{ Red meat } \\
\hline Baseline footprint ${ }^{\mathrm{b}}$ & $306,814,577,669$ & $19,976,304,599$ & $705,870,333$ & $327,527,655$ \\
\hline Adjusted footprint ${ }^{\mathrm{c}}$ & $69,040,966,416$ & $4,495,168,989$ & $158,838,509$ & $73,701,928$ \\
\hline Net change & $(237,773,611,253)$ & $(15,481,135,610)$ & $(547,031,824)$ & $(253,825,727)$ \\
\hline \multicolumn{5}{|l|}{ Vegetables/beans } \\
\hline Baseline footprint & $118,127,809,039$ & $15,449,699,461$ & $1,442,640,966$ & $59,080,864$ \\
\hline Adjusted footprint & $193,294,087,177$ & $25,280,546,375$ & $2,360,612,382$ & $96,674,795$ \\
\hline Net change & $75,166,278,138$ & $9,830,846,913$ & $917,971,416$ & $37,593,931$ \\
\hline \multicolumn{5}{|l|}{ Nuts/seeds } \\
\hline Baseline footprint & $13,645,316,625$ & $2,911,394,091$ & $8,710,612$ & $3,762,501$ \\
\hline Adjusted footprint & $24,436,517,860$ & $5,213,827,987$ & $15,599,274$ & $6,738,020$ \\
\hline Net change & $10,791,201,236$ & $2,302,433,896$ & $6,888,662$ & $2,975,519$ \\
\hline \multicolumn{5}{|l|}{ Fruits } \\
\hline Baseline footprint & $32,908,561,924$ & $13,358,845,365$ & $845,518,805$ & $17,612,961$ \\
\hline Adjusted footprint & $85,895,067,437$ & $34,868,096,824$ & $2,206,899,679$ & $45,971,819$ \\
\hline Net change & $52,986,505,513$ & $21,509,251,459$ & $1,361,380,875$ & $28,358,858$ \\
\hline
\end{tabular}

${ }^{\mathrm{a} C h a n g e s}$ that would result in net expenditure are reported in positive figures, while net savings are reported in parentheses. These figures represent net changes for a single day, assuming complete adherence to the nutritionally recommended intake of red meat, vegetables/beans, nuts/seeds, and fruits by the adult population

${ }^{\mathrm{b}}$ Baseline footprint refers to the environmental footprint associated with current consumption levels across MENA countries

${ }^{\mathrm{c}}$ Adjusted footprint refers to the environmental footprint associated with recommended consumption levels across MENA countries
Increased fruit consumption in Egypt and Algeria would require net blue water expenditures of approximately 6.1 and 3.2 billion liters per day, respectively, or approximately $43 \%$ of the blue water footprint associated with increased fruit consumption in the region ( 21.5 billion liters per day). Algeria's increased vegetables/beans consumption would require 1.7 billion liters of additional blue water per day as compared to the blue water use associated with current consumption levels, or approximately $18 \%$ of the blue water footprint associated with increased vegetables/ beans' consumption in the region $(9.8$ billion liters per day). The largest energy use footprint expenditures were attributable to Morocco and Algeria for increased fruits and vegetables/beans' consumption, to Egypt and Iraq for increased fruits consumption, and to Saudi Arabia for increased vegetables/beans consumption. Increased fruits consumption in Egypt, Algeria, Morocco, and Iraq would jointly account for 0.9 billion MJ of additional energy use per day, or approximately $64 \%$ of the energy use footprint associated with increased fruits consumption in the region (1.4 billion MJ per day). Increased vegetables/beans' consumption in Algeria, Morocco, and Saudi Arabia would jointly account for 0.4 billion MJ of additional energy use per day, or approximately $44 \%$ of the energy use footprint associated with increased vegetables/beans' consumption in the region ( 0.9 billion MJ). The largest GHGE footprint expenditures were shown in Egypt and Algeria for increased consumption of fruits and vegetables/beans and in Morocco and Saudi Arabia for increased consumption of vegetables/beans. Based on current consumption levels of nuts/seeds, only three countries (Lebanon, Syria, and Tunisia) exceed recommended levels of nuts/seeds' consumption.

Table 3 shows the net changes in environmental footprints resulting from different combinations of dietary changes in each MENA country. In all countries, the combined effect of reducing consumption of red meat and increasing consumption of vegetables/beans would lead to net savings in all environmental footprints, except for energy use. Decreased consumption of red meat and increased consumption of vegetables/beans and nuts/seeds combined will continue to result in net savings in all environmental footprints except for energy use across all countries, with the exception of Libya, Morocco, and Yemen, where net expenditure in blue water is noted. Combining decreased consumption of red meat with increased consumption of vegetables/beans and nuts/seeds would result in net savings in all environmental footprints 
Table 2 Net changes in total water, blue water, energy use, and GHGE as a result of shifting to recommended dietary changes, at the national level

\begin{tabular}{|c|c|c|c|c|}
\hline & \multicolumn{4}{|c|}{ Environmental footprint of recommended dietary changes-national level ${ }^{\mathrm{a}}$} \\
\hline & Total water $(\mathrm{L})$ & Blue water $(\mathrm{L})$ & Energy use (MJ) & GHGE $\left(\mathrm{kg} \mathrm{CO}_{2} \mathrm{eq}\right)$ \\
\hline \multicolumn{5}{|l|}{ Algeria } \\
\hline Red meat & $(53,586,889,734)$ & $(3,488,973,829)$ & $(123,284,219)$ & $(57,204,545)$ \\
\hline Vegetables/beans & $13,223,162,924$ & $1,729,430,985$ & $161,488,448$ & $6,613,480$ \\
\hline Nuts/seeds & $2,148,201,524$ & $458,344,896$ & $1,371,324$ & 592,336 \\
\hline Fruits & $7,834,724,712$ & $3,180,414,755$ & $201,297,373$ & $4,193,216$ \\
\hline \multicolumn{5}{|l|}{ Bahrain } \\
\hline Red meat & $(1,374,985,399)$ & $(89,523,540)$ & $(3,163,348)$ & $(1,467,811)$ \\
\hline Vegetables/beans & $452,888,057$ & $59,232,322$ & $5,530,915$ & 226,509 \\
\hline Nuts/seeds & $35,784,227$ & $7,635,000$ & 22,843 & 9,867 \\
\hline Fruits & $201,252,148$ & $81,695,953$ & $5,170,766$ & 107,712 \\
\hline \multicolumn{5}{|l|}{ Egypt } \\
\hline Red meat & $(44,422,135,746)$ & $(2,892,268,423)$ & $(102,199,407)$ & $(47,421,078)$ \\
\hline Vegetables/beans & $8,830,178,666$ & $1,154,881,375$ & $107,838,938$ & $4,416,357$ \\
\hline Nuts/seeds & $3,930,718,130$ & $838,666,471$ & $2,509,210$ & $1,083,839$ \\
\hline Fruits & $15,032,447,717$ & $6,102,246,126$ & $386,228,279$ & $8,045,502$ \\
\hline \multicolumn{5}{|l|}{ Iraq } \\
\hline Red meat & $(19,384,850,044)$ & $(1,262,122,784)$ & $(44,597,589)$ & $(20,693,523)$ \\
\hline Vegetables/beans & $7,568,515,060$ & $989,870,920$ & $92,430,817$ & $3,785,344$ \\
\hline Nuts/seeds & $875,142,633$ & $186,722,314$ & 558,655 & 241,308 \\
\hline Fruits & $5,113,247,684$ & $2,075,663,023$ & $131,374,537$ & $2,736,657$ \\
\hline \multicolumn{5}{|l|}{ Jordan } \\
\hline Red meat & $(5,254,577,784)$ & $(342,118,837)$ & $(12,088,899)$ & $(5,609,315)$ \\
\hline Vegetables/beans & $772,558,170$ & $101,041,335$ & $9,434,900$ & 386,390 \\
\hline Nuts/seeds & $171,950,564$ & $36,687,742$ & 109,766 & 47,413 \\
\hline Fruits & $135,388,111$ & $54,959,218$ & $3,478,523$ & 72,461 \\
\hline \multicolumn{5}{|l|}{ Kuwait } \\
\hline Red meat & $(4,560,039,276)$ & $(296,898,323)$ & $(10,491,015)$ & $(4,867,888)$ \\
\hline Vegetables/beans & $1,435,111,076$ & $187,695,302$ & $17,526,356$ & 717,762 \\
\hline Nuts/seeds & $108,857,290$ & $23,226,025$ & 69,490 & 30,016 \\
\hline Fruits & $636,026,933$ & $258,187,686$ & $16,341,423$ & 340,407 \\
\hline \multicolumn{5}{|l|}{ Lebanon } \\
\hline Red meat & $(2,544,094,257)$ & $(165,642,722)$ & $(5,853,049)$ & $(2,715,846)$ \\
\hline Vegetables/beans & $864,405,842$ & $113,053,908$ & $10,556,594$ & 432,327 \\
\hline Nuts/seeds & $(218,558,872)$ & $(46,632,191)$ & $(139,519)$ & $(60,264)$ \\
\hline Fruits & $742,632,733$ & $301,463,062$ & $19,080,443$ & 397,464 \\
\hline \multicolumn{5}{|l|}{ Libya } \\
\hline Red meat & $(3,979,694,072)$ & $(259,112,789)$ & $(9,155,849)$ & $(4,248,364)$ \\
\hline Vegetables/beans & $2,520,204,080$ & $329,612,442$ & $30,778,101$ & $1,260,464$ \\
\hline Nuts/Seeds & $119,777,384$ & $25,555,960$ & 76,461 & 33,027 \\
\hline Fruits & $1,345,021,665$ & $545,995,795$ & $34,557,606$ & 719,868 \\
\hline \multicolumn{5}{|l|}{ Morocco } \\
\hline Red meat & $(16,927,351,864)$ & $(1,102,118,222)$ & $(38,943,767)$ & $(18,070,119)$ \\
\hline Vegetables/beans & $10,392,879,373$ & $1,359,263,870$ & $126,923,488$ & $5,197,932$ \\
\hline Nuts/seeds & $985,412,123$ & $210,249,649$ & 629,047 & 271,713 \\
\hline Fruits & $5,757,525,761$ & $2,337,200,164$ & $147,927,956$ & $3,081,480$ \\
\hline \multicolumn{5}{|l|}{ Oman } \\
\hline Red meat & $(3,328,296,533)$ & $(216,701,129)$ & $(7,657,217)$ & $(3,552,990)$ \\
\hline Vegetables/beans & $1,178,563,912$ & $154,142,013$ & $14,393,263$ & 589,451 \\
\hline
\end{tabular}


Table 2 (continued)

\begin{tabular}{|c|c|c|c|c|}
\hline & \multicolumn{4}{|c|}{ Environmental footprint of recommended dietary changes-national level ${ }^{\mathrm{a}}$} \\
\hline & Total water $(\mathrm{L})$ & Blue water $(\mathrm{L})$ & Energy use (MJ) & GHGE $\left(\mathrm{kg} \mathrm{CO} \mathrm{Cl}_{2}\right.$ eq \\
\hline Nuts/seeds & $130,698,029$ & $27,886,012$ & 83,432 & 36,038 \\
\hline Fruits & $612,543,139$ & $248,654,715$ & $15,738,055$ & 327,839 \\
\hline \multicolumn{5}{|l|}{ Palestine } \\
\hline Red meat & $(2,474,919,658)$ & $(161,138,852)$ & $(5,693,903)$ & $(2,642,002)$ \\
\hline Vegetables/beans & $1,007,538,386$ & $131,773,927$ & $12,304,606$ & 503,914 \\
\hline Nuts/seeds & $148,975,975$ & $31,785,834$ & 95,100 & 41,078 \\
\hline Fruits & $712,170,616$ & $289,097,322$ & $18,297,781$ & 381,160 \\
\hline \multicolumn{5}{|l|}{ Qatar } \\
\hline Red meat & $(2,619,049,340)$ & $(170,522,952)$ & $(6,025,493)$ & $(2,795,862)$ \\
\hline Vegetables/beans & $862,653,645$ & $112,824,742$ & $10,535,195$ & 431,451 \\
\hline Nuts/seeds & $68,161,200$ & $14,543,020$ & 43,511 & 18,794 \\
\hline Fruits & $314,340,232$ & $127,602,737$ & $8,076,335$ & 168,238 \\
\hline \multicolumn{5}{|l|}{ Saudi Arabia } \\
\hline Red meat & $(23,406,065,923)$ & $(1,523,939,005)$ & $(53,848,965)$ & $(24,986,211)$ \\
\hline Vegetables/beans & $9,101,388,120$ & $1,190,352,316$ & $111,151,095$ & $4,552,001$ \\
\hline Nuts/seeds & $1,725,915,960$ & $368,245,140$ & $1,101,754$ & 475,897 \\
\hline Fruits & $3,747,838,185$ & $1,521,391,025$ & $96,293,107$ & $2,005,877$ \\
\hline \multicolumn{5}{|l|}{ Syria } \\
\hline Red meat & $(18,798,310,407)$ & $(1,223,933,939)$ & $(43,248,172)$ & $(20,067,386)$ \\
\hline Vegetables/beans & $5,293,924,131$ & $692,381,730$ & $64,652,277$ & $2,647,722$ \\
\hline Nuts/seeds & $(587,075,035)$ & $(125,259,592)$ & $(374,765)$ & $(161,878)$ \\
\hline Fruits & $3,430,138,069$ & $1,392,424,383$ & $88,130,446$ & $1,835,841$ \\
\hline \multicolumn{5}{|l|}{ Tunisia } \\
\hline Red meat & $(7,697,606,500)$ & $(501,181,311)$ & $(17,709,433)$ & $(8,217,273)$ \\
\hline Vegetables/beans & $2,620,572,199$ & $342,739,387$ & $32,003,851$ & $1,310,662$ \\
\hline Nuts/seeds & $(57,918,973)$ & $(12,357,717)$ & $(36,973)$ & $(15,970)$ \\
\hline Fruits & $1,976,149,843$ & $802,194,889$ & $50,773,165$ & $1,057,653$ \\
\hline \multicolumn{5}{|l|}{ UAE } \\
\hline Red meat & $(13,546,784,845)$ & $(882,013,829)$ & $(31,166,295)$ & $(14,461,329)$ \\
\hline Vegetables/beans & $2,438,648,435$ & $318,945,943$ & $29,782,099$ & $1,219,674$ \\
\hline Nuts/seeds & $161,694,472$ & $34,499,480$ & 103,219 & 44,585 \\
\hline Fruits & $1,404,482,559$ & $570,133,249$ & $36,085,333$ & 751,692 \\
\hline \multicolumn{5}{|l|}{ Yemen } \\
\hline Red meat & $(13,867,959,872)$ & $(902,925,124)$ & $(31,905,203)$ & $(14,804,187)$ \\
\hline Vegetables/beans & $6,603,086,060$ & $863,604,396$ & $80,640,473$ & $3,302,491$ \\
\hline Nuts/seeds & $1,043,464,604$ & $222,635,851$ & 666,105 & 287,720 \\
\hline Fruits & $3,990,575,407$ & $1,619,927,358$ & $102,529,748$ & $2,135,792$ \\
\hline
\end{tabular}

Countries are listed in alphabetical order

${ }^{a}$ Changes that would result in net expenditure are reported in positive figures, while net savings are reported in parentheses. These figures represent net changes for a single day, assuming complete adherence to the nutritionally recommended intake of red meat, vegetables/beans, nuts/seeds, and fruits by the adult population in Jordan and UAE. If increased fruits consumption is added to the combination of dietary changes, countries will continue to have savings in total water and GHGE, with the exception of Libya and Morocco showing net expenditure in total water; net savings in blue water will be expected only in Jordan. 
Table 3 Net changes in total water, blue water, energy use, and GHGE as a result of shifting to indicated combinations of recommended dietary changes, at the national level

\begin{tabular}{|c|c|c|c|c|}
\hline & \multicolumn{4}{|c|}{ Environmental footprint of recommended dietary changes (national level) } \\
\hline & Total water $(\mathrm{L})$ & Blue water $(\mathrm{L})$ & Energy use (MJ) & GHGE (kg CO2 eq) \\
\hline \multicolumn{5}{|l|}{ Algeria } \\
\hline $\mathrm{RM}+\mathrm{V} / \mathrm{B}$ & $(40,363,726,809)$ & $(1,759,542,844)$ & $38,204,229$ & $(50,591,065)$ \\
\hline $\mathrm{RM}+\mathrm{V} / \mathrm{B}+\mathrm{N} / \mathrm{S}$ & $(38,215,525,285)$ & $(1,612,582,617)$ & $39,575,553$ & $(49,998,729)$ \\
\hline $\mathrm{RM}+\mathrm{V} / \mathrm{B}+\mathrm{N} / \mathrm{S}+\mathrm{F}$ & $(30,380,800,573)$ & $1,567,832,137$ & $240,872,926$ & $(45,805,514)$ \\
\hline \multicolumn{5}{|l|}{ Bahrain } \\
\hline $\mathrm{RM}+\mathrm{V} / \mathrm{B}$ & $(922,097,342)$ & $(30,291,219)$ & $2,367,567$ & $(1,241,302)$ \\
\hline $\mathrm{RM}+\mathrm{V} / \mathrm{B}+\mathrm{N} / \mathrm{S}$ & $(886,313,116)$ & $(27,843,190)$ & $2,390,410$ & $(1,231,435)$ \\
\hline $\mathrm{RM}+\mathrm{V} / \mathrm{B}+\mathrm{N} / \mathrm{S}+\mathrm{F}$ & $(685,060,968)$ & $53,852,763$ & $7,561,176$ & $(1,123,723)$ \\
\hline \multicolumn{5}{|l|}{ Egypt } \\
\hline $\mathrm{RM}+\mathrm{V} / \mathrm{B}$ & $(35,591,957,080)$ & $(1,737,387,047)$ & $5,639,532$ & $(43,004,721)$ \\
\hline $\mathrm{RM}+\mathrm{V} / \mathrm{B}+\mathrm{N} / \mathrm{S}$ & $(31,661,238,950)$ & $(1,468,483,398)$ & $8,148,741$ & $(41,920,881)$ \\
\hline $\mathrm{RM}+\mathrm{V} / \mathrm{B}+\mathrm{N} / \mathrm{S}+\mathrm{F}$ & $(16,628,791,233)$ & $4,633,762,727$ & $394,377,020$ & $(33,875,379)$ \\
\hline \multicolumn{5}{|l|}{ Iraq } \\
\hline $\mathrm{RM}+\mathrm{V} / \mathrm{B}$ & $(11,816,334,983)$ & $(272,251,864)$ & $47,833,227$ & $(16,908,179)$ \\
\hline $\mathrm{RM}+\mathrm{V} / \mathrm{B}+\mathrm{N} / \mathrm{S}$ & $(10,941,192,350)$ & $(212,382,639)$ & $48,391,883$ & $(16,666,871)$ \\
\hline $\mathrm{RM}+\mathrm{V} / \mathrm{B}+\mathrm{N} / \mathrm{S}+\mathrm{F}$ & $(5,827,944,667)$ & $1,863,280,383$ & $179,766,419$ & $(13,930,214)$ \\
\hline \multicolumn{5}{|l|}{ Jordan } \\
\hline $\mathrm{RM}+\mathrm{V} / \mathrm{B}$ & $(4,482,019,614)$ & $(241,077,501)$ & $(2,653,999)$ & $(5,222,925)$ \\
\hline $\mathrm{RM}+\mathrm{V} / \mathrm{B}+\mathrm{N} / \mathrm{S}$ & $(4,310,069,049)$ & $(229,314,222)$ & $(2,544,233)$ & $(5,175,512)$ \\
\hline $\mathrm{RM}+\mathrm{V} / \mathrm{B}+\mathrm{N} / \mathrm{S}+\mathrm{F}$ & $(4,174,680,939)$ & $(174,355,004)$ & 934,290 & $(5,103,051)$ \\
\hline \multicolumn{5}{|l|}{ Kuwait } \\
\hline $\mathrm{RM}+\mathrm{V} / \mathrm{B}$ & $(3,124,928,199)$ & $(109,203,021)$ & $7,035,341$ & $(4,150,126)$ \\
\hline $\mathrm{RM}+\mathrm{V} / \mathrm{B}+\mathrm{N} / \mathrm{S}$ & $(3,016,070,910)$ & $(101,756,004)$ & $7,104,831$ & $(4,120,110)$ \\
\hline $\mathrm{RM}+\mathrm{V} / \mathrm{B}+\mathrm{N} / \mathrm{S}+\mathrm{F}$ & $(2,380,043,976)$ & $156,431,682$ & $23,446,254$ & $(3,779,703)$ \\
\hline \multicolumn{5}{|l|}{ Lebanon } \\
\hline $\mathrm{RM}+\mathrm{V} / \mathrm{B}$ & $(1,679,688,415)$ & $(52,588,814)$ & $4,703,545$ & $(2,283,519)$ \\
\hline $\mathrm{RM}+\mathrm{V} / \mathrm{B}+\mathrm{N} / \mathrm{S}$ & $(1,898,247,287)$ & $(67,540,605)$ & $4,564,026$ & $(2,343,784)$ \\
\hline $\mathrm{RM}+\mathrm{V} / \mathrm{B}+\mathrm{N} / \mathrm{S}+\mathrm{F}$ & $(1,155,614,554)$ & $233,922,457$ & $23,644,469$ & $(1,946,320)$ \\
\hline \multicolumn{5}{|l|}{ Libya } \\
\hline $\mathrm{RM}+\mathrm{V} / \mathrm{B}$ & $(1,459,489,991)$ & $70,499,653$ & $21,622,252$ & $(2,987,900)$ \\
\hline $\mathrm{RM}+\mathrm{V} / \mathrm{B}+\mathrm{N} / \mathrm{S}$ & $(1,339,712,607)$ & $78,693,722$ & $21,698,713$ & $(2,954,873)$ \\
\hline $\mathrm{RM}+\mathrm{V} / \mathrm{B}+\mathrm{N} / \mathrm{S}+\mathrm{F}$ & $5,309,058$ & $624,689,517$ & $56,256,319$ & $(2,235,005)$ \\
\hline \multicolumn{5}{|l|}{ Morocco } \\
\hline $\mathrm{RM}+\mathrm{V} / \mathrm{B}$ & $(6,534,472,492)$ & $257,145,648$ & $87,979,721$ & $(12,872,187)$ \\
\hline $\mathrm{RM}+\mathrm{V} / \mathrm{B}+\mathrm{N} / \mathrm{S}$ & $(5,549,060,369)$ & $324,558,498$ & $88,608,767$ & $(12,600,474)$ \\
\hline $\mathrm{RM}+\mathrm{V} / \mathrm{B}+\mathrm{N} / \mathrm{S}+\mathrm{F}$ & $208,465,392$ & $2,661,758,662$ & $236,536,723$ & $(9,518,994)$ \\
\hline \multicolumn{5}{|l|}{ Oman } \\
\hline $\mathrm{RM}+\mathrm{V} / \mathrm{B}$ & $(2,149,732,621)$ & $(62,559,116)$ & $6,736,046$ & $(2,963,539)$ \\
\hline $\mathrm{RM}+\mathrm{V} / \mathrm{B}+\mathrm{N} / \mathrm{S}$ & $(2,019,034,592)$ & $(53,617,957)$ & $6,819,478$ & $(2,927,501)$ \\
\hline $\mathrm{RM}+\mathrm{V} / \mathrm{B}+\mathrm{N} / \mathrm{S}+\mathrm{F}$ & $(1,406,491,453)$ & $195,036,758$ & $22,557,533$ & $(2,599,662)$ \\
\hline \multicolumn{5}{|l|}{ Palestine } \\
\hline $\mathrm{RM}+\mathrm{V} / \mathrm{B}$ & $(1,467,381,272)$ & $(29,364,926)$ & $6,610,703$ & $(2,138,088)$ \\
\hline $\mathrm{RM}+\mathrm{V} / \mathrm{B}+\mathrm{N} / \mathrm{S}$ & $(1,318,405,297)$ & $(19,173,357)$ & $6,705,803$ & $(2,097,010)$ \\
\hline $\mathrm{RM}+\mathrm{V} / \mathrm{B}+\mathrm{N} / \mathrm{S}+\mathrm{F}$ & $(606,234,681)$ & $269,923,965$ & $25,003,584$ & $(1,715,850)$ \\
\hline \multicolumn{5}{|l|}{ Qatar } \\
\hline $\mathrm{RM}+\mathrm{V} / \mathrm{B}$ & $(1,756,395,695)$ & $(57,698,210)$ & $4,509,701$ & $(2,364,411)$ \\
\hline $\mathrm{RM}+\mathrm{V} / \mathrm{B}+\mathrm{N} / \mathrm{S}$ & $(1,688,234,494)$ & $(53,035,246)$ & $4,553,213$ & $(2,345,616)$ \\
\hline $\mathrm{RM}+\mathrm{V} / \mathrm{B}+\mathrm{N} / \mathrm{S}+\mathrm{F}$ & $(1,373,894,262)$ & $74,567,490$ & $12,629,548$ & $(2,177,379)$ \\
\hline
\end{tabular}


Table 3 (continued)

\begin{tabular}{|c|c|c|c|c|}
\hline & \multicolumn{4}{|c|}{ Environmental footprint of recommended dietary changes (national level) } \\
\hline & Total water $(\mathrm{L})$ & Blue water $(\mathrm{L})$ & Energy use (MJ) & GHGE (kg CO2 eq) \\
\hline \multicolumn{5}{|l|}{ Saudi Arabia } \\
\hline $\mathrm{RM}+\mathrm{V} / \mathrm{B}$ & $(14,304,677,803)$ & $(333,586,689)$ & $57,302,130$ & $(20,434,211)$ \\
\hline $\mathrm{RM}+\mathrm{V} / \mathrm{B}+\mathrm{N} / \mathrm{S}$ & $(12,578,761,843)$ & $(215,515,364)$ & $58,403,884$ & $(19,958,314)$ \\
\hline $\mathrm{RM}+\mathrm{V} / \mathrm{B}+\mathrm{N} / \mathrm{S}+\mathrm{F}$ & $(8,830,923,658)$ & $1,305,875,662$ & $154,696,991$ & $(17,952,437)$ \\
\hline \multicolumn{5}{|l|}{ Syria } \\
\hline $\mathrm{RM}+\mathrm{V} / \mathrm{B}$ & $(13,504,386,276)$ & $(531,552,209)$ & $21,404,105$ & $(17,419,664)$ \\
\hline $\mathrm{RM}+\mathrm{V} / \mathrm{B}+\mathrm{N} / \mathrm{S}$ & $(14,091,461,311)$ & $(571,714,493)$ & $21,029,340$ & $(17,581,541)$ \\
\hline $\mathrm{RM}+\mathrm{V} / \mathrm{B}+\mathrm{N} / \mathrm{S}+\mathrm{F}$ & $(10,661,323,242)$ & $820,709,890$ & $109,159,786$ & $(15,745,700)$ \\
\hline \multicolumn{5}{|l|}{ Tunisia } \\
\hline $\mathrm{RM}+\mathrm{V} / \mathrm{B}$ & $(5,077,034,301)$ & $(158,441,923)$ & $14,294,419$ & $(6,906,610)$ \\
\hline $\mathrm{RM}+\mathrm{V} / \mathrm{B}+\mathrm{N} / \mathrm{S}$ & $(5,134,953,274)$ & $(162,404,208)$ & $14,257,445$ & $(6,922,581)$ \\
\hline $\mathrm{RM}+\mathrm{V} / \mathrm{B}+\mathrm{N} / \mathrm{S}+\mathrm{F}$ & $(3,158,803,431)$ & $639,790,681$ & $65,030,611$ & $(5,864,927)$ \\
\hline \multicolumn{5}{|l|}{ UAE } \\
\hline $\mathrm{RM}+\mathrm{V} / \mathrm{B}$ & $(11,108,136,411)$ & $(563,067,886)$ & $(1,384,195)$ & $(13,241,655)$ \\
\hline $\mathrm{RM}+\mathrm{V} / \mathrm{B}+\mathrm{N} / \mathrm{S}$ & $(10,946,441,939)$ & $(552,006,235)$ & $(1,280,976)$ & $(13,197,070)$ \\
\hline $\mathrm{RM}+\mathrm{V} / \mathrm{B}+\mathrm{N} / \mathrm{S}+\mathrm{F}$ & $(9,541,959,380)$ & $18,127,014$ & $34,804,357$ & $(12,445,378)$ \\
\hline \multicolumn{5}{|l|}{ Yemen } \\
\hline $\mathrm{RM}+\mathrm{V} / \mathrm{B}$ & $(7,264,873,812)$ & $(39,320,728)$ & $48,735,270$ & $(11,501,696)$ \\
\hline $\mathrm{RM}+\mathrm{V} / \mathrm{B}+\mathrm{N} / \mathrm{S}$ & $(6,221,409,208)$ & $32,063,541$ & $49,401,375$ & $(11,213,976)$ \\
\hline $\mathrm{RM}+\mathrm{V} / \mathrm{B}+\mathrm{N} / \mathrm{S}+\mathrm{F}$ & $(2,230,833,801)$ & $1,651,990,899$ & $151,931,123$ & $(9,078,183)$ \\
\hline
\end{tabular}

Countries are listed in alphabetical order

With regard to sensitivity analysis conducted to assess the implications of possible inaccuracies in the point estimates of per-food environmental footprints, pairwise comparisons of changes in consumption in food groups across footprints are illustrative. The alternative point estimates that were applied are presented as S6A, and their corresponding net environmental impacts across the MENA region are presented within S6B. In 8 of 12 possible cases (joint total water footprint of red meat and vegetables/beans; joint blue water footprint of red meat and vegetables/beans; joint blue water footprint of red meat and nuts/seeds; joint blue water footprint of red meat and fruits; joint energy use footprint of red meat and vegetables/ beans; joint energy use footprint of red meat and fruits; joint GHGE of red meat and vegetables/beans; and joint GHGE of red meat and fruits), variation in the point estimates of per-unit footprint triggered a change in the mathematical sign of the combined footprint, reinforcing a conclusion that the results are sensitive to the point estimates applied (an illustrative result for sensitivity analysis applied to the joint total water footprint of red meat and vegetables/beans is presented as S6C).

Results of the sensitivity analysis conducted with regard to the rate of food loss and waste in MENA countries show that in only one pairwise comparison-the joint blue water footprint of red meat and fruits - did variation in the rate of food loss and waste result in a change in the mathematical sign of the combined footprint, suggesting that the results of this study are reasonably robust to the assumed rates of food loss and waste (S7).

Assessment was also made as to whether it might be possible to satisfy incremental consumption not through additional food production but rather through the use of food that would otherwise be lost or wasted. Incremental increases in consumption of fruits, vegetables/beans, and nuts/seeds could not be fully satisfied through a corresponding reduction in food loss and waste under the baseline assumption of $19 \%$ loss and waste, with a single exception: Only Jordan could, in theory, satisfy the additional consumption of fruits through a redirection of fruits that would otherwise be lost or wasted along the value chain (S8).

\section{Discussion}

To our knowledge, this study is the first to assess the impact of shifting towards healthier food consumption patterns on environmental sustainability in the MENA region. This assessment of partial dietary changes and the 
environmental implications thereof is intended to generate regional data and inform decisions on dietary guidelines and policies that are both nutritionally adequate and environmentally sustainable, including identification of potential tradeoffs. This research serves as a model that could be further expanded to include the environmental impact of other protective or harmful foods, and thereby enhance the positive impact on the health and environment of the MENA population. This analysis is particularly important for the MENA region given pressing needs to make informed decisions on production and imports, and the challenges of persistent food insecurity, the high and rising prevalence of diet-related NCDs, and the depletion of environmental resources that is expected to decline further as a result of climate change.

This study reports on four foods that were shown to be associated with NCDs. Foods termed harmful were associated with increased death rates from NCDs, while foods termed protective were associated with lower death rates from NCDs (Afshin et al. 2015). Thus, the choice of the food groups was based on availability of consumption and environmental footprint data for these foods and the evidence for the association of these foods with chronic diseases. This study takes a quantitative approach to analyze the environmental impact of dietary shifts from current consumption levels to recommended intakes, to help MENA countries to understand the impact of implementing those shifts. By providing data for the MENA region, this study complements existing quantitative studies from primarily developed countries that have looked into the environmental impacts of dietary change. Moreover, this study supports the qualitative data that has been reported for the Mediterranean diet being a healthy and sustainable diet (Burlingame and Dernini 2011; Dernini and Berry 2015). This analysis assumes that individuals would shift their food consumption patterns across these selected food groups, but does not assume that the total caloric and nutrients intake would adjust to exactly match recommended caloric intake.

This study shows that, at the regional level, shifting to healthier food consumption pattern by reducing red-meat consumption alone would generate savings in the four environmental footprints studied. This result is particularly important as it provides the evidence for the high impact on environmental savings that would benefit the MENA population from recommending decreases in red-meat consumption. From a nutritional and health standpoint, redmeat consumption is important to consider in light of the recommended $100 \mathrm{~g} /$ week consumption of this food group defined as the exposure level associated with the lowest level of harm (Afshin et al. 2015). In fact, red-meat intake is strongly associated with NCD risk, including diabetes and certain cancers, particularly colorectal cancer (Afshin et al. 2015; International Agency for Research on Cancer 2015; Domingo and Nadal 2017), as well as cardiovascular disease (Bovalino et al. 2016) and heart failure in women (Kaluza et al. 2015). Hence, it is clear that a reduction in consumption of red meat should deliver both nutritional and environmental benefits across the countries of the MENA region.

As expected, increased consumption of vegetables/ beans, nuts/seeds, and fruits, on the other hand, would generate net expenditure in all environmental footprints. In terms of magnitude of net expenditure, nuts/seeds were associated with the lowest net expenditure across all four footprints. This low consumption of nuts/seeds was previously reported to be associated with increased morbidity and mortality from coronary heart disease and diabetes (Micha et al. 2012, 2017; Afshin et al. 2015). The highest net expenditure in blue water and energy use came from the change in fruits consumption, while increases in vegetables/beans consumption were associated with the highest net expenditure in total water and GHGE. Low consumption of fruits and vegetables is also associated with increased outcomes and deaths from cardiovascular diseases, diabetes, and certain types of cancer (Micha et al. 2012, 2017; Afshin et al. 2015).

Considering the combined dietary change in all four food groups across the MENA region, the estimated savings in total water footprint associated with reduced redmeat consumption would exceed additional expenditure in total water footprint associated with increased consumption of all three foods (vegetables/beans, nuts/seeds, and fruits) combined. Decreasing red-meat consumption would be the only contributor to total GHGE savings, and would exceed the counterbalance in GHGE expenditure generated by the change in consumption of other food groups combined. For blue water and energy use, the combined increased consumption of vegetables/beans, nuts/seeds, and fruits would outweigh the savings associated with reduced red-meat consumption.

However, if shifts in consumption were implemented in a stepwise manner and the reduction in red-meat consumption was pursued simultaneously with increased consumption of one other food group, then the net environmental effect of these paired changes may vary and allows for identification of tradeoffs. For example, the combined result of a reduction in red-meat consumption with increased consumption of vegetables/beans would jointly result in net savings of total water, blue water, and GHGE, but net expenditure of energy use across the MENA region. This combined change in consumption of red meat and vegetables/beans may be appropriate to consider, because vegetables/beans could also compensate for the caloric and nutritional (protein) value of foregone red-meat intake. Indeed, vegetables/beans, being a rich 
source of protein, are considered a suitable alternative. To red meat that can compensate for the reduction in red meat in terms of proteins and energy. Alternatively, the combined result of reductions in red-meat consumption with increased consumption of nuts/seeds would jointly result in net savings across all four environmental footprints at the regional level. Finally, the combined result of a reduction in red-meat consumption with increased consumption of fruits would jointly result in net savings of total water and GHGE, but net expenditure of blue water and energy use. Comparing the environmental impact of paired comparisons, the red-meat-nuts/seeds paired change is associated with net savings across four footprints, followed by redmeat-vegetables/beans resulting in net savings across three footprints, and finally red-meat-fruits associated with net savings in only two footprints. In terms of magnitude of net impact, the red-meat-nuts/seeds paired change yields the highest net savings across all four footprints. The redmeat-vegetables/beans paired changes result in higher net savings of blue water and energy use in terms of magnitude than the red-meat-fruits paired changes; however, the redmeat-fruits paired change results in a higher net savings in total water and GHGE than the red-meat-vegetables/beans paired change.

Looking at the sub-regional level, shifting consumption across these four foods would result in savings of total water and GHGE, but net expenditure of both blue water and energy use in almost all MENA countries, with the exceptions of Jordan, where additional net savings in blue water were noted, as well as in Libya and Morocco, where net expenditure in total water was observed. The combined net result would be a median reduction over baseline in total water footprint by approximately $20 \%$ and a reduction in GHGE by approximately $45 \%$ but a median increase in blue water footprint by approximately $27 \%$ and an increase in energy use by approximately $56 \%$. These results are generally consistent with a systematic review primarily from developed countries which studied the effect of dietary change towards healthy food guidelines and showed median reductions in GHGE and water use of approximately 20-30\%; energy use was not considered in the systematic review (Aleksandrowicz et al. 2016). The range of potential outcomes suggests that there are opportunities for win-win outcomes if selected dietary changes are pursued.

Alternatively, if consumption patterns shift through decreasing red meat and increasing vegetables/beans simultaneously, then all MENA countries would benefit from net savings across total water, blue water, and GHGE, but net expenditure in energy use. These paired changes are advantageous in being associated with improvement in nutritional health, with generally positive environmental impact. Given the nutritional value of vegetables/beans, this paired comparison seems to be the most appropriate from both a nutritional and environmental perspective.

The results of this analysis are principally driven by current consumption levels for each of the four food groups; the per-unit environmental footprints associated with each food group; and population figures. Indeed, the largest potential impact on environmental footprints is observed in heavily populated countries including Algeria, Egypt, Iraq, and Saudi Arabia. However, even less populated countries could experience a potentially significant environmental impact resulting from dietary shifts, particularly for those food groups for which the gap between current and recommended intakes is wide, such as red meat, vegetables/beans, and fruits. In fact, all countries over-consume red meat and under-consume vegetables/ beans and fruits, on a per-capita basis; most countries under-consume nuts/seeds at the per-capita level, except Lebanon, Syria, and Tunisia. Therefore, all countries need to increase their consumption from vegetables/beans, nuts/ seeds, and fruits with the exception of the aforementioned three countries, where nuts/seeds' consumption is higher than recommended levels. The data also show that Jordan is the only country in which the combined effect of shifting to all four recommended dietary intakes would result in net savings in the blue water footprint. This result is driven by the fact that Jordanian current consumption of fruits, vegetables/beans, and nuts/seeds' falls close to recommended levels, but red-meat consumption exceeds the recommended level by a wide margin.

These collective recommended dietary changes are in line with available literature which advocates that what is 'good for you' is 'good for the environment' (Barilla Center for Food and Nutrition 2014) and that nutritionally recommended foods of plant origin often have a lower environmental impact, while animal-based foods tend to have higher environmental impact than plant-based foods (Barilla Center for Food and Nutrition 2010; Eat and Sustainia 2015). Recommendations for sustainable diets have, therefore, often called for reduced meat consumption in favor of a plant-based diet, or, in other words, for animal protein sources that can be produced with a lower environmental footprint. The results of this study are in conformity with the literature in terms of the beneficial environmental impact of reduced consumption of animalbased foods, specifically red meat (Aleksandrowicz et al. 2016; Nelson et al. 2016). However, the implications of increased consumption of protective foods (vegetables/ beans, nuts/seeds, and fruits) are less clear as even healthy foods require resources to produce. Adopting nutritional recommendations to consume more protective foods would require more natural resources for their production. This is of particular interest for countries with large populations, or countries that are scarce in environmental resources like 
water. For example, in the MENA region, water is a limiting factor for agricultural production, whereby internal renewable water resources in most countries are well below the threshold of water scarcity $\left(1000 \mathrm{~m}^{3} /\right.$ capita/year $)$ (Abdel Gelil and Saab 2015). Tradeoffs can be considered in lieu of the reported positive health effects of the recommended foods.

These results are in accordance with studies which have shown higher environmental impact of shifts to certain types of sustainable diets depending on shifts in dietary patterns and the environmental footprints applied. In the United States, a shift from the current US diet to USDA dietary recommendations was estimated to increase energy use by $38-43 \%$, blue water by $10-16 \%$, and GHGE by 6-12\%, mainly due to higher recommended intakes of foods such as fruits and vegetables that exhibit high resource use and emissions per calorie (Heller and Keoleian 2015; Tom et al. 2016). A study from Germany reported that shifting to certain dietary styles such as ovolacto vegetarian and vegan diets would reduce GHGE but significantly increase blue water use; this was mainly attributed to nuts/seeds intake in these diets. The same study found, however, that adopting other dietary recommendations would reduce GHGE and blue water use (Meier and Christen 2013). In France, substituting fruits and vegetables for red and processed meat showed no or even net-positive impact on diet-associated GHGE. This was due to the high amounts of fruits and vegetables that were needed to maintain the caloric content of the diet, and the result implies that such substitutions may be desirable for health but not necessarily for the environment (Vieux et al. 2012). A study of the effects of adopting the Mediterranean diet also identified environmental tradeoffs: the change showed increased water demand that was largely attributed to fruits, but decreased GHGE per capita (Davis et al. 2016).

It is important to note that achievement of improved health and nutritional benefits ought to be prioritized, with minimal environmental harm. To offset these environmental costs, changes in consumption patterns might be pursued jointly so as to offset higher consumption of protective foods with reduced consumption of harmful foods (as illustrated in the cases of red meat-vegetables/beans and red meat-nuts/seeds above). In cases, where changes in food consumption deliver improved nutrition, but at a higher environmental cost, then tradeoffs must be made. The question then is how to achieve the nutritionally necessary change with the minimal net environmental impact policy options to secure protective foods and support their consumption could be to support domestic production of varieties that are least impactful on the environment, to turn to imports as an alternative to local production drawing on scarce resources like water, or to reduce and reclaim food loss or waste within existing production systems. It is thus useful to consider the role of food loss and waste within these results, using local figures and in making recommendations to both improve food consumption and minimize environmental impact. When looking across all MENA countries, the environmental impact of dietary changes affecting a selected food group would be lower in magnitude if a lower level of food loss and waste was assumed as compared to baseline (e.g., 10\% as compared to 19\%). Conversely, if the level of food loss and waste was in fact higher for the selected food group than is assumed in the baseline case, then the magnitude of environmental savings or expenditures would be heightened under modified dietary patterns. If the rate of food loss and waste was higher than assumed in this analysis, then more countries, in addition to Jordan, might be able to satisfy incremental demand through redirection of otherwise lost or wasted food (S8). This result demonstrates the importance of obtaining more accurate estimates of actual food loss and waste for specific food groups of interest, and within individual MENA countries, and points to opportunities, where governments might focus to determine whether food can be recovered for human consumption at an acceptable cost.

\section{Limitations}

This study presents some limitations. It relies on regional (total water, blue water) and global (energy use, GHGE) environmental footprint figures primarily based on LCA, which may be considered a potential source of error. LCA studies vary in their assumptions, system boundaries, and data quality, which may result in non-comparable measures (Cucurachi et al. 2016). However, such footprints remain widely used throughout the sustainability literature (Jones et al. 2016) despite ongoing debate over design and application of LCA-derived footprints (Hoekstra 2016; Chenoweth et al. 2014; Perry 2014; Garnett 2009). Second, LCA is optimally undertaken for specific agricultural and production systems, but available environmental footprints have most often been calculated for developed country food production systems (Jones et al. 2016). This study has applied regional footprints for total water and blue water as available. Unfortunately, MENA country-specific environmental footprints for energy use and GHGE conducted using a single, consistent, and transparent methodology are not widely available, and global footprints are applied instead. Insofar as production methods in MENA countries is similar to those in developed countries, the use of global footprint data may be appropriate, and to the extent that they are significantly different, the use of global footprint data would introduce error into the present calculations. Furthermore, though it would be more accurate to assess 
the marginal environmental footprints of additional food consumption, reflecting how and where the food would be produced, this study applies average environmental footprints per-food group (Cucurachi et al. 2016). This consideration is relevant to this study, because the additional fruits, vegetables/beans, and nuts/seeds to be produced could not, in most cases, be sourced through a reduction in the proportion of food loss and waste within the value chain (S8). Our analysis assumes for practical reasons that marginal production would be sourced from the MENA region. If marginal demand was instead sourced from a different point of origin, environmental footprints should correctly correspond to the producing country; such estimates would require information on the marginal volumes imported from each point of origin, which is beyond the scope of this analysis. Because marginal footprint figures are not available, the inclusion of a sensitivity analysis within this paper allows for the inaccuracy of average figures.

\section{Conclusions and recommendations}

The results of this study provide evidence for the beneficial environmental effects of reducing consumption of red meat across all MENA countries. They also show that a simultaneous decrease in red meat and increase in vegetables/ beans consumption offer a good opportunity to move towards more sustainable and healthy diets in the MENA region.

Further research on the environmental impact of shifting dietary patterns that would cover more recommended food consumption patterns is needed across the MENA region, thus expanding the evidence for policy makers to revise their Food-Based Dietary Guidelines to include the dimension of sustainability, and eventually provide both health and environmental benefits to populations.

Acknowledgements The authors thank Mr. Jeremy Zidek (Futura Foods) for comments on an early draft of this article.

\section{Compliance with ethical standards}

Conflict of interest The authors declare that they have no conflict of interest.

Open Access This article is distributed under the terms of the Creative Commons Attribution 4.0 International License (http://creative commons.org/licenses/by/4.0/), which permits unrestricted use, distribution, and reproduction in any medium, provided you give appropriate credit to the original author(s) and the source, provide a link to the Creative Commons license, and indicate if changes were made.

\section{References}

Afshin A, Micha R, Khatibzadeh S, Fahimi S, Shi P, Powles J, Singh J, Yakoob MY, Abdollahi M, Al-Hooti S, Farzadfar F, Houshiar$\operatorname{rad}$ A, Hwalla N, Koksal E, Musaiger A, Pekcan G, Sibai AM, Zaghloul S, Danaei G, Ezzati M, Mozaffarian D (2015) The impact of dietary habits and metabolic risk factors on cardiovascular and diabetes mortality in countries of the Middle East and North Africa in 2010: a comparative risk assessment analysis. BMJ Open 5:e006385. https://doi.org/10.1136/bmjo pen-2014-006385

Aleksandrowicz L, Green R, Joy EJM, Smith P, Haines A (2016) The impacts of dietary change on greenhouse gas emissions, land use, water use, and health: a systematic review. PLoS One 11(11):e0165797. https://doi.org/10.1371/journal.pone.0165797

Allan T (2000) The Middle-East water question: hydropolitics and the global economy. I.B Tauris, London

Barilla Center for Food and Nutrition (2014) Sustainable diets-good for you, good for the environment. Barilla Center for Food and Nutrition, Parma. https://www.barillacfn.com/m/publications/ bcfn-sustainable-diets-policy-paper-eng.pdf. Accessed $15 \mathrm{Sept}$ 2017

Barilla Center for Food and Nutrition (2010) Double pyramid: healthy food for people, sustainable food for the planet. Barilla Center for Food and Nutrition, Parma. http://www.barillacfn.com/wpcontent/uploads/2010/06/pp_doppia_piramide_alimentazione_ eng.pdf. Accessed 5 May 2015

Bovalino S, Charleson G, Szoeke C (2016) The impact of red and processed meat consumption on cardiovascular disease risk in women. Nutrition 32(3):349-354

Burlingame B, Dernini S (2011) Sustainable diets: the Mediterranean diet as an example. Public Health Nutr 14(12A):2285-2287. https://doi.org/10.1017/S1368980011002527

Capone R, Iannetta M, El Bilali H, Colonna N, Debs P, Dernini S, Maiani G, Intorre F, Polito A, Turrini A, Cardone G, Lorusso F, Belsanti V (2013) A preliminary assessment of the environmental sustainability of the current Italian dietary pattern: water footprint related to food consumption. J Food Nutr Res 1(4):59-67. https://doi.org/10.12691/jfnr-1-4-5

Chenoweth J, Hadjikakou M, Zoumides C (2014) Quantifying the human impact on water resources: a critical review of the water footprint concept. Hydrol Earth Syst Sci 18:2325-2342

Cucurachi S, Yang Y, Bergesen J, Qin Y, Suh S (2016) Challenges in assessing in the environmental consequences of dietary changes. Environ Syst Decis. https://doi.org/10.1007/s10669-016-9589-2

Dabalen A, Paul S (2014) Effect of conflict on dietary diversity: evidence from Côte d'Ivoire. World Dev 58:143-158. https:// doi.org/10.1016/j.worlddev.2014.01.010

Davis KF, Gephart JA, Emery KA, Leach AM, Galloway JN, D'Odorico P (2016) Meeting future food demand with current agricultural resources. Glob Environ Change 39:125-132

Dernini S, Berry EM (2015) Mediterranean diet: from a healthy diet to a sustainable dietary pattern. Front Nutr 2:15. https://doi.org/ $10.3389 /$ fnut.2015.00015

Domingo JL, Nadal M (2017) Carcinogenicity of consumption of red meat and processed meat: a review of scientific news since the IARC decision. Food Chem Toxicol 105:256-261

EAT, Sustainia (2015) Eat in sustainia: taste the food systems of tomorrow. Retrieved from http://sustainia.me/resources/publica tions/Eat_in_Sustainia_2015.pdf

Fahed AC, El-Hage-Sleiman AKM, Farhat TI, Nemer GM (2012) Diet, genetics, and disease: a focus on the Middle East and North Africa region. J Nutr Metab. https://doi.org/10.1155/2012/ 109037 
Food and Agriculture Organization (FAO) (2012) Sustainable diets and biodiversity: directions and solutions for policy, research and action. In: Burlingame B, Dernini S (eds) Proceedings of the International Scientific Symposium on Biodiversity and Sustainable Diets: united against hunger, Food and Agriculture Organization, Rome http://www.fao.org/docrep/016/i3004e/i3004e. pdf. Accessed 19 Mar 2015

Food and Agriculture Organization (FAO) (2016a) Emissionsagriculture: agriculture total. FAOStat, Food and Agriculture Organization, Rome http://faostat3.fao.org/home/E. Accessed 02 Feb 2016

Food and Agriculture Organization (FAO) (2016b) Emissions-land use: land use total. FAOStat, Food and Agriculture Organization, Rome http://faostat3.fao.org/home/E. Accessed 02 Feb 2016

Food and Agriculture Organization (FAO) (2016c) Water withdrawal by sector, around 2010. AQUASTAT Database, Food and Agriculture Organization, Rome. Retrieved from http://www. fao.org/nr/water/aquastat/tables/WorldData-Withdrawal_eng. pdf. Accessed 31 Mar 2017

Food and Agriculture Organization (FAO), IFAD, UNICEF, WHO (2017) The state of food security and nutrition in the world 2017: building resilience for peace and food security. Food and Agriculture Organization, Rome

Garnett T (2009) Livestock-related greenhouse gas emissions: impacts and options for policy makers. Environ Sci Policy 12:491-503. https://doi.org/10.1016/j.envsci.2009.01.006

Germani A, Vitiello V, Giusti AM, Pinto A, Donini LM, del Balzo V (2014) Environmental and economic sustainability of the Mediterranean diet. Int J Food Sci Nutr 65(8):1008-1012. https://doi.org/10.3109/09637486.2014.945152

Green R, Milner J, Dangour A, Haines A, Chalabi Z, Markandya A, Spadaro J, Wilkinson P (2015) The potential to reduce greenhouse gas emissions in the UK through healthy and realistic dietary change. Clim Change 129:235-265. https://doi.org/10. 1007/s10584-015-1329-y

Heller MC, Keoleian GA (2015) Greenhouse gas emission estimates of US dietary choices and food loss. J Ind Ecol 19(3):391-401. https://doi.org/10.1111/jiec.12174

Hendrie G, Ridoutt B, Wiedmann T, Noakes M (2014) Greenhouse gas emissions and the Australian diet-comparing dietary recommendations with average intakes. Nutrients 6(1):289-303. https://doi.org/10.3390/nu6010289

HLPE (2017) Nutrition and food systems. A report by the High Level Panel of Experts on Food Security and Nutrition of the Committee on World Food Security, Rome

Hoekstra A (2016) A critique on the water-scarcity weighted water footprint in LCA. Ecol Ind 66:564-573

International Agency for Research on Cancer (2015) IARC Monographs evaluate consumption of red meat and processed meat. Press Release $\mathrm{N}^{\circ}$ 240, 26 October 2015. Retrieved from: http:// www.db.zs-intern.de/uploads/1446460802-WHO.pdf

International Diabetes Federation (2013) IDF diabetes atlas, sixth edition. International Diabetes Foundation, Brussels. Retrieved from www.idf.org/diabetesatlas

Johnston J, Fanzo J, Cogill B (2014) Understanding sustainable diets: a descriptive analysis of the determinants and processes that influence diets and their impact on health, food security, and environmental sustainability. Adv Nutr 5:418-429

Jones AD, Hoey L, Blesh J, Miller L, Green A, Fink Shapiro L (2016) A systematic review of the measurement of sustainable diets. Adv Nutr 7(4):641-664. https://doi.org/10.3945/an.115.011015

Kaluza J, Åkesson A, Wolk A (2015) Long-term processed and unprocessed red meat consumption and risk of heart failure: a prospective cohort study of women. Int J Cardiol 193:42-46

Lang T, Barling D (2012) Food security and food sustainability: reformulating the debate. Geogr J 178(4):313-326
Lipinski B, Hanson C, Lomax J, Kitinoja L, Waite R, Searchinger T (2013) Reducing food loss and waste. Working paper, Installment 2 of Creating a Sustainable Food Future. World Resources Institute, Washington, DC http://www.wri.org/sites/default/files/ reducing_food_loss_and_waste.pdf

Meerman J, Garrett J, Wüstefeld M (2013) Development partners and country programming in nutrition and agriculture. SCN News 40:10-18

Meier T, Christen O (2013) Environmental impacts of dietary recommendations and dietary styles: germany as an example. Environ Sci Technol 47(2):877-888. https://doi.org/10.1021/ es $302152 \mathrm{v}$

Mekonnen M, Hoekstra A (2011) National water footprint accounts: the green, blue and grey water footprint of production and consumption. Volume 2: appendices. UNESCO Institute for Water Education, Paris

Micha R, Kalantarian S, Wirojratana P, Byers T, Danaei G, Elmadfa I, Ding E, Giovannucci E, Powles J, Smith-Warner S, Ezzati M, Mozaffarian D, on behalf of the Global Burden of Diseases, Nutrition and Chronic Disease Expert Group (2012) Estimating the global and regional burden of suboptimal nutrition on chronic disease: methods and inputs to the analysis. Eur J Clin Nutr 66:119-129

Micha R, Peñalvo JL, Cudhea F, Imamura F, Rehm CD, Mozaffarian D (2017) JAMA 317(9):912-924. https://doi.org/10.1001/jama. 2017.0947

Moomaw W, Griffin T, Kurczak K, Lomax J (2012) The critical role of global food consumption patterns in achieving sustainable food systems and food for all: a UNEP discussion paper. Division of Technology, Industry and Economics, United Nations Environment Programme, Paris

Nelson M, Hamm M, Hu F, Abrams S, Griffin T (2016) Alignment of healthy dietary patterns and environmental sustainability: a systematic review. Adv Nutr 7(6):1005-1025. https://doi.org/10. 3945/an.116.012567

Perry C (2014) Water footprints: path to enlightenment, or false trail? Agric Water Manag 134:119-125

Popkin B (2000) Urbanization and the nutrition transition. IFPRI Brief 7, International Food Policy Research Institute, Washington

Sadik A (2014) The state of food security and agricultural resources. In: Sadik A, El-Solh M, Saab N (eds) Annual report of the Arab Forum for environment and development, 2014. Arab Forum for Environment and Development, Beirut, Lebanon

Sibai AM, Nasreddine L, Mokdad AH, Adra N, Tabet M, Hwalla N (2010) Nutrition transition and cardiovascular disease risk factors in Middle East and North Africa countries: reviewing the evidence. Ann Nutr Metab 57:193-203

Tom M, Fischbeck P, Hendrickson C (2016) Energy use, blue water footprint, and greenhouse gas emissions for current food consumption patterns and dietary recommendations in the US. Environ Syst Decis 36:92-103

Tukker A, Goldbohm RA, de Koning A, Verheijden M, Kleijn R, Wolf O, Pérez-Domínguez I, Ruenda-Cantuche J (2011) Environmental impacts of changes to healthier diets in Europe. Ecol Econ 70(10):1776-1788. https://doi.org/10.1016/j.ecolecon. 2011.05 .001

United Nations, Department of Economic and Social Affairs, Population Division (UN) (2013) World population prospects: the 2012 revision, DVD edn. United Nations, New York

United Nations Development Programme (UNDP) (2016a) Sustainable development goals (SDGs). Webpage. http://www.undp. org/content/undp/en/home/sdgoverview/post-2015-develop ment-agenda.html. Accessed 1 Feb 2016

United Nations Development Programme (UNDP) (2016b) Sustainable development goals. http://www.undp.org/content/dam/ 
undp/library/corporate/brochure/SDGs_Booklet_Web_En.pdf. Accessed 1 Feb 2016

Vanham D (2013) The water footprint of Austria for different diets. Water Sci Technol 67(4):824-830

Vanham D, Mekonnen MM, Hoekstra AY (2013) The water footprint of the EU for different diets. Ecol Ind 32:1-8

Vanham D, del Pozo S, Pekcan AG, Keinan-Boker L, Trichopoulou A, Gawlik BM (2016) Water consumption related to different diets in Mediterranean cities. Sci Total Environ 573:96-105. https://doi.org/10.1016/j.scitotenv.2016.08.111

Vieux F, Darmon N, Touazi D, Soler LG (2012) Greenhouse gas emissions of self-selected individual diets in France: changing the diet structure or consuming less? Ecol Econ 75:91-101

Westhoek H, Lesschen JP, Rood T, Wagner S, De Marco A, MurphyBokem D, Leip A, van Grinsven H, Sutton M, Oenema O (2014) Food choices, health and environment: effects of cutting Europe's meat and dairy intake. Glob Environ Change 26:196-205. https://doi.org/10.1016/j.gloenvcha.2014.02.004

Woertz E, Keulertz M (2015) Food trade relations of the Middle East and North Africa with tropical countries. Food Secur 7:1101-1111. https://doi.org/10.1007/s12571-0502-5
World Bank (2016) Agricultural land (\% of land area). Databank. Retrieved from http://data.worldbank.org/indicator/AG.LND. AGRI.ZS/countries/1W-ZQ?display=graph. Accessed 1 Feb 2016

World Bank, Food and Agriculture Organization of the United Nations (FAO), International Fund for Agricultural Development (IFAD) (2009) Improving food security in Arab countries. World Bank, Washington, DC. Retrieved from https://openknowledge. worldbank.org/handle/10986/23966. Accessed 19 June 2018

World Health Organization (WHO) (2011) Regional strategy on nutrition 2010-2019 and plan of action. WHO Regional Office for the Eastern Mediterranean, Cairo

World Resources Institute (2015) CAIT climate data explorer. World Resources Institute, Washington, DC. Retrieved from http:// www.wri.org/resources/data-sets/cait-historical-emissions-datacountries-us-states-unfccc. Accessed 2 Feb 2016

Yusuf S, Reddy S, Ounpuu S, Anand S (2001) Global burden of cardiovascular diseases. Part I: general considerations, the epidemiologic transition, risk factors, and impact of urbanization. Circulation 104(22):2746-2753 